Hollahan, M. B., G. W. Beadle, and H. G. Calhoun. 1949. Linkage studies with biochemical mutants of Neurospora crassa. Genetics 34: 493-507.

Lindegren, C. C. 1935. The genetics of Neurospora. VII. Developmental competition between different genotypes within the ascus. Zeitschr. Indukt. Abstamm. u. Vererb. 68: 331-335.

McClintock, Barbara. 1945. Neurospora. I. Preliminary observations of the chromosomes of Neurospora crassa. Amer. Jour. Bot. 32: 671-678.

MacLaren, J. A. 1952. The effects of certain purines and pyrimidines upon the production of riboflavin by Eremothecium ashbyii. Jour. Bact. 63: 233-241.

McNutt, W. S. 1954a. The role of adenine in the biogenesis of riboflavin by Eremothecium ashbyii. Abstr. Amer. Soc. Plant Physiol.

- - . 1954h. The direct contribution of adenine to the biogenesis of riboflavin by Eremothecium ashbyii. Jour. Biol. Chem. 210: 511-519.

Mitchell, H. K., and M. B. Holluahan. 1946. Neurospora IV. A temperature-sensitive riboflavinless mutant. Amer. Jour. Bot. 33: 31-35.
Mrtchele, M. B. 1955. Aberrant recombination of pyridoxine mutants of Neurospora. Proc. National Acad. Sci. (U.S.) 41: 215-220.

—-, AND H. K. Mitchell. 1954. A partial map of link. age group $\mathrm{D}$ in Neurospora crassa. Proc. National Acad. Sci. (U.S.) 40: 436-440.

Plaut, G. W. E. 1954. Biosynthesis of riboflavin. II. Incorporation of $\mathrm{C}^{14}$ labeled compounds into ring $\mathrm{A}$. Jour. Biol. Chem. 211: 111-116.

Singleton, J. R. 1948. Cytogenetic studies of Neurospora crassa. Thesis. California Inst. Tech. Pasadena.

- 1953. Chromosome morphology and chromosome cycle in the ascus of Neurospora crassa. Amer. Jour. Bot. 40: 124-144.

SNELL, E. E. 1954. Metabolic significance of B-vitamins. Physiol. Rev. 33: 509-524.

Tatum, E. L., R. W. Barratt, N. Fries, and D. Bonner. 1950. Biochemical mutant strains of Neurospora produced by physical and chemical treatment. Amer. Jour. Bot. 37: 38-46.

W.IJER, J. 1954. A genetical investigation into the td-locus of Neurospora crasss. Genetica 27: 173-254.

\title{
ABSORPTION OF $\mathrm{CO}^{60}$ BY LEAVES OF YOUNG PLANTS AND ITS TRANSLOCATION THROUGH THE PLANT ${ }^{1}$
}

\author{
Felix G. Gustafson
}

A NuMBER of recent investigations have had as their object the study of absorption of organic and inorganic compounds by leaves and the subsequent distribution of the absorbed chemicals through the plant. Most of these investigations were concerned with the entrance of growth regulators, hut some dealt with nutrition or other aspects of plant physiology (Boynton, 1954). It was found that many chemicals applied to the leaves are quickly absorbed and translocated into other parts of the plant, but there is room for further studies on factors concerned, and that has been the plan of the present work. Radioactive isotopically enriched chlorides of zinc- 65 and cobalt- 60 have been used, hut all the work reported was done with cobalt-60.

Methods.-Black Valentine bean seedlings 2-3 weeks old have been used as plant material except where otherwise stated. Five-hundredths-ml. of $\mathrm{Co}^{60} \mathrm{Cl}_{2}$, with an activity of $30 \mu \mathrm{c} / \mathrm{ml}$., were applied with a syringe within a lanolin ring (Mitchell and Linder, 1949) near the apex of one of the primary leaves. In hot weather, when the lanolin had a tendency to melt, a ring was outlined with ink and care was taken that the isotope solution did not extend to this boundary. Tween 20 , at a concentration of 2.3 per cent, was used as a spreader.

Each experiment was terminated after $6 \mathrm{hr}$., and as a preliminary to harvesting, the treated area and several millimeters beyond the lanolin circle were

\footnotetext{
1 Received for publication June 27, 1955.

Paper from Department of Botany, University of Michigan, Number 1039. This investigation has been aided financially by the Michigan Memorial Phoenix Project.
}

removed with a cork borer and discarded. Each plant was divided into three parts: the treated leaf, the rest of the top, and the roots. These were dried separately at $90^{\circ} \mathrm{C}$. for about $24 \mathrm{hr}$., subsequently ground coarsely, and stored in screw-top vials until counted.

The gamma-ray emission from the cobalt- 60 was determined with a scintillation counter. Preliminary experiments were run to determine whether there was any absorption of gamma rays by the plant material; the count was the same whether the isotope was evaporated on a counting pan or mixed with dry bean leaves and evaporated.

Two types of experiments were set up, sometimes concurrently, but usually on different days. In one group of experiments the plants were in the light before and during the treatment, whereas in the other the plants had been in the dark from 24 to $72 \mathrm{hr}$. before the application of the isotope and were left there during the treatment. There were many variations of these arrangements.

RESults.-Preliminary experiments were run to determine the length of time necessary for the isotope to be distributed to all parts of the plant. Table 1 shows a typical experiment with plants two weeks old. Two hours seem to be enough time for the cobalt-60 to be distributed to all parts of the plant, and, as the time lapse increased, a greater amount was present in all parts. Even though two hours were enough, it was decided to continue the experiments for six hours.

Experiments in light.-In table 2 are combined several experiments on effect of light intensity, 
TABLE 1. Time relation of absorption and translocation. Figures denote counts/minute/part

\begin{tabular}{|c|c|c|c|c|c|c|}
\hline $\begin{array}{c}\text { Time in } \\
\text { hours }\end{array}$ & $\begin{array}{c}\text { Treated } \\
\text { leaf }\end{array}$ & $\begin{array}{c}\text { Bud and } \\
\text { opposite } \\
\text { leaf }\end{array}$ & $\begin{array}{l}\text { All of } \\
\text { stem }\end{array}$ & $\begin{array}{l}\text { Older } \\
\text { part } \\
\text { of root }\end{array}$ & Root tips & Total \\
\hline 1 & 52 & 32 & 77 & 19 & 0 & 180 \\
\hline 2 & 106 & 70 & 167 & 88 & 52 & 433 \\
\hline 3 & 257 & 343 & 154 & 258 & 171 & 1183 \\
\hline
\end{tabular}

temperature and state of turgor of the plant on the absorption and translocation. In our greenhouse the control of the experimental conditions is not very good. Accordingly, attempts were made to have a large divergence of the conditions studied and then small variations in temperature and light intensity would not be so important.

In the two experiments cited the higher light intensity increased the absorption. The experimental conditions prevented the use of the full light intensity of the summer sun and one can only surmise what would happen if a light intensity of $10,000 \mathrm{f}$. $-\mathrm{c}$. were used. The literature is contradictory on the effect of light on absorption by leaves. Weaver and De Rose (1946) found that the absorption and translocation of 2,4-D was less rapid in the shade than in the sun. But Penfound and Minyard (1947) found that water hyacinths sprayed with butyl ester of 2,4-D died sooner when kept in shade than when in full sunlight. The results of the present experiments agree with those of Weaver and De Rose.

A temperature effect was also observed; higher temperature increasing the amount of absorption. Rice (1948) has reported a similar influence on the absorption of 2,4-D. Bennett and Thomas (1954) observed that the systemic insecticide, Schradan, was absorbed and translocated more rapidly at a higher temperature.

The influence of the turgor condition of the leaf was striking. The plants that were turgid from the beginning of the experiment had a much higher activity than those that were wilted for part of the time.

The addition of oils and other substances to sprays to increase the absorption is a very common practice. Hull (1953) has reported that $S / V$ Sovaspray 100 increases the absorption and translocation of 2,4,5-trichlorophenoxyacetic acid when used on seedlings of velvet mesquite. In the present study S/V Sovaspray 100 was incorporated into the $\mathrm{Co}^{60}$ solution at the rate of 16.6 per cent. The emulsion was applied to the leaf in the usual way. It was observed that the oil emulsion dried less rapidly than the aqueous solution. The results are given in table 3 , and it is readily seen that the addition of $\mathrm{S} / \mathrm{V}$ Sovaspray 100 to the $\mathrm{Co}^{60}$ solution greatly increased the absorption over that from the control solution without it. There is also more translocation, but the percentage of that absorbed is smaller than in the control so that it can hardly be said that the translocation has been speeded up. It seems that this substance should be a good additive to sprays intended for application to leaves.

Experiments in dark. - Several investigators (Emmert and Klinker, 1952; Mitchell and Brown, 1949; Rohrbaugh and Rice, 1949; Weintraub and Brown, 1950) have suggested or demonstrated that sugar aids the absorption of growth regulators by leaves in the dark and the subsequent translocation. It was decided to learn whether this also applied to cobalt-60. The cobalt chloride solution was applied to leaves of plants in the light and also to leaves

TABLE 2. Influence of various factors on absorption and translocation of cobalt-60. The upper figure for each experiment denotes the total count per min. for the plant and the lower figure denotes the translocation out of the treated leaf. In the experiments on light the figures are the average for 6 plants, in temperature 7 plants, and in the wilting experiments average of 5 plants

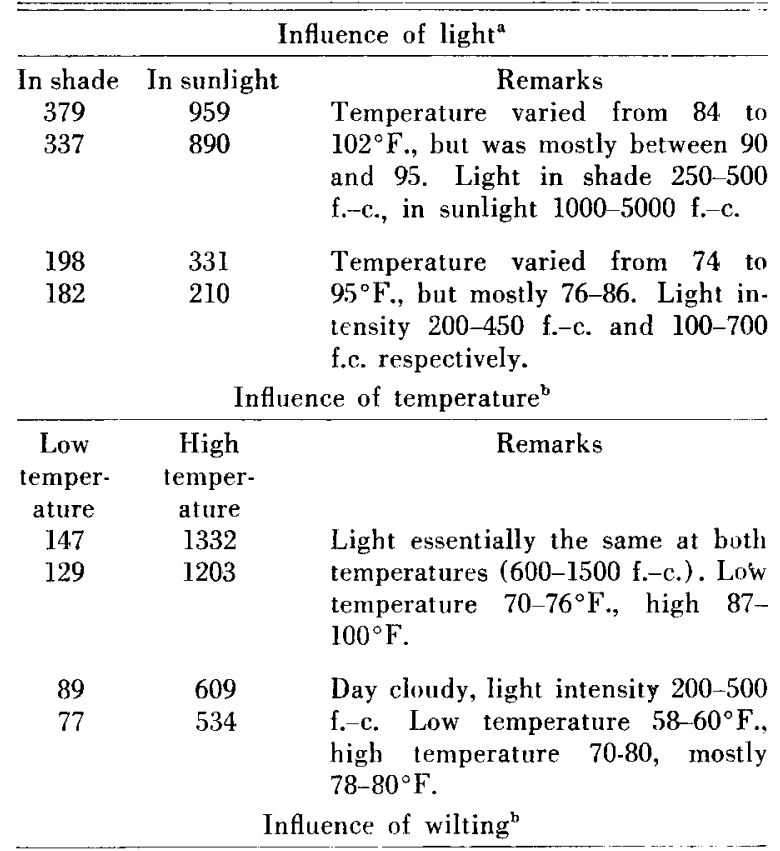

\begin{tabular}{|c|c|c|c|}
\hline Not & & & Remarks \\
\hline wilted & $\begin{array}{l}\text { Wilted } \\
3-4 \mathrm{~h}\end{array}$ & $\begin{array}{l}\text { Wilted } \\
4-5 \mathrm{~h}\end{array}$ & \\
\hline 1251 & 666 & 484 & No temperature or light measure- \\
\hline 940 & 490 & 303 & $\begin{array}{l}\text { ments made, but at } 5: 45 \text { the tem- } \\
\text { perature was still } 90^{\circ} \mathrm{F} \text {. }\end{array}$ \\
\hline 1133 & 932 & 351 & Temperature mostly near 100 but \\
\hline 937 & 585 & 176 & $\begin{array}{l}\text { as low as } 90^{\circ} \mathrm{F} \text {. Light instensity } \\
1000-2000 \mathrm{f} .-\mathrm{c} \text {. }\end{array}$ \\
\hline 1362 & 853 & & Temperature mostly near 90 but \\
\hline 1066 & 623 & & $\begin{array}{l}\text { as low as } 80^{\circ} \mathrm{F} \text {. Light intensity } \\
1000-2500 \mathrm{f} .-\mathrm{c} \text {. }\end{array}$ \\
\hline
\end{tabular}

${ }^{a}$ For these two experiments forty-three and forty-five day old cucumber plants were used.

"For these experiments Black Valentine been plants two weeks old were used. 
TARLE 3. Influence of $S / V$ Sovaspray 100 mixed with Co $^{60}$ on absorption and translocation, when plants were in light. The upper figure in each experiment denotes counts/minute/plant; the lower figure denotes the amount translocated from the treated leaf-that is, counts/minute for the whole plant minus the treated leaf. Tween 20 was present in all solutions

\begin{tabular}{rcc}
$\begin{array}{c}\text { Cobalt plus } \\
\text { Cobalt } \\
\text { alone }\end{array}$ & $\begin{array}{c}\text { S/ Sovaspray } \\
100\end{array}$ & \multicolumn{1}{c}{ Remarks } \\
\hline 1120 & 11828 & Al end of 2.5 hrs. solution had \\
597 & 3288 & $\begin{array}{l}\text { dried and a drop of distilled } \\
\text { water was added to each spot. }\end{array}$ \\
& & Sun bright. \\
660 & 1197 & Day cloudy with rain at noon. \\
354 & 535 & Temperature in greenhouse high. \\
1805 & 13939 & Day sunny. \\
933 & 5936 &
\end{tabular}

on plants that had been in the dark for at least $24 \mathrm{hr}$. To other plants in dark was applied cobalt chloride solution to which had been added sucrose. Table 4 gives the results of some of these experiments. In the dark, plants may absorb the cobalt, but it is not translocated out of the treated leaf. The addition of sucrose to the cobalt solution changes this situation and considerable translocation occurs, though it is not as great as in those plants maintained in the light. The question arose as to the effectiveness of other sugars, and glucose, fructose and maltose were also tried. These also aided somewhat in translocation, though they seem not quite so effective as sucrose. The sugar alcohol, mannitol, was employed in a number of experiments because structurally it is so much like glucose, yet it is considered not to be a source of energy. Its use might offer an answer to the question of whether a source of energy is necessary for translocation. Glycine, as an example of amino acids, was also used. With one possible exception these last two compounds were of no essential value in the translocation of cobalt-60 from the leaf to which it was applied. Whether this is due to their lack of penetration into the leaf or to their low energy release, or to some other factor, cannot be determined from the present information.

Some years ago, Went (1948) found that sucrose sprayed on the leaves of the tomato plant entered the plant. In some experiments in the present investigation sucrose was not added to the cobalt -60 solution but was sprayed on the leaves except for an area where the cobalt solution was to be placed. While not so effective as when added to the solution, this method of applying sucrose did aid in translocation.

In other experiments not included in the table, plants were moved from the light to darkness at the time of the applications of the isotope solution. In such experiments the absorption and translocation was not much lower than in the plants left in the light. In still other experiments plants were moved from the dark room to the light when solution was applied to the primary leaf. In these plants there

TAвLE 4. A comparison of translocation of cobalt-60, in two-weeks-old Black Valentine bean plants, in light and in the dark, when various sugars or other organic compounds were added to the cobalt solution. Previous to the initiation of the experiment the dark plants were in the dark for 24 to $36 \mathrm{hr}$. Figures denote counts per minute

\begin{tabular}{|c|c|c|c|c|c|c|c|c|c|c|c|c|c|c|c|}
\hline \multirow{2}{*}{\multicolumn{2}{|c|}{$\frac{\text { In light }}{\text { Co.alone }}$}} & \multicolumn{14}{|c|}{ In the dark before and during the experiment } \\
\hline & & \multicolumn{2}{|c|}{ Co alone } & \multicolumn{2}{|c|}{ Co + sucrose } & \multicolumn{2}{|c|}{$\mathrm{Co}+$ glucose } & \multicolumn{2}{|c|}{ Co + fructose } & \multirow{2}{*}{\multicolumn{2}{|c|}{$\begin{array}{c}\text { Co }+ \text { maltose } \\
\text { leaf tran. }\end{array}$}} & \multicolumn{2}{|c|}{ Co + mannitol } & \multicolumn{2}{|c|}{ Co+glycine } \\
\hline leaf" & tran. & leaf & tran. & leaf & tran. & leaf & tran. & leaf & tran. & & & leaf & tran. & leaf & tran. \\
\hline \multirow[t]{5}{*}{101} & 660 & 133 & 0 & 863 & 0 & 0 & 0 & & & & & 29 & 0 & 3170 & 0 \\
\hline & & 19 & 0 & 1469 & 43 & 0 & 0 & & & & & 170 & 0 & 1603 & 0 \\
\hline & & 59 & 0 & 300 & 374 & 60 & 0 & & & & & 0 & 0 & 2399 & 193 \\
\hline & & 1014 & 0 & 886 & 42 & 1092 & 319 & & & & & 490 & 0 & 1953 & 0 \\
\hline & & 595 & 0 & 2346 & 103 & 1365 & 0 & & & & & 314 & 15 & & \\
\hline 419 & 1139 & 483 & 0 & 1593 & 411 & 1961 & 769 & & & & & 542 & 0 & 772 & 17 \\
\hline \multirow[t]{2}{*}{1068} & 1415 & 322 & 0 & 656 & 625 & 4062 & 1058 & & & & & 1231 & 0 & 3552 & 15 \\
\hline & & 879 & 0 & & & 1308 & 720 & & & & & 337 & 15 & & \\
\hline 1035 & 708 & 832 & 0 & 682 & 12 & 721 & 106 & 101 & 0 & 856 & 18 & 206 & 0 & 1082 & 0 \\
\hline 1706 & 627 & 287 & 0 & 482 & 176 & 1710 & 0 & 0 & 0 & 1234 & 44 & 121 & 0 & & \\
\hline 825 & 578 & & & & & & & & & & & & & & \\
\hline 605 & 1036 & 44 & 0 & 1181 & I28 & 216 & 0 & 401 & 35 & 839 & 39 & 546 & 0 & 237 & 0 \\
\hline 1824 & 1104 & 0 & 0 & 619 & 0 & 128 & 0 & 473 & 116 & 294 & 0 & 52 & 0 & 542 & 0 \\
\hline 384 & 472 & 151 & 0 & 465 & 93 & 365 & 28 & 96 & 12 & 1086 & 0 & 276 & 0 & 138 & 0 \\
\hline 203 & 281 & 147 & 0 & 663 & 139 & 558 & 27 & 557 & 0 & 295 & 0 & 14 & 0 & 63 & 0 \\
\hline
\end{tabular}

"Note: Leaf refers to the treated leaf, tran. is the total count for the rest of the plant.

In this lable six experiments, each one consisting of from 9 to 16 plants, are recorded. The results of each experiment are given separately. The experiments are separated from each other by extra space. 
was also considerable absorption and translocation, but not as much as in those in the light over a period of days or those just moved from the light to the dark - all of which demonstrates that sugars play a part in the translocation by plants.

Discussion.- There is considerable controversy as to whether chemicals applied to leaves enter exclusively through the stomata. Weaver and De Rose (1946) do not think the entrance is through the stomata. Roberts et al. (1948) present good anatomical evidence in the leaves of the McIntosh apple for the possibility of entrance through areas of pectinaceous material occurring between the epidermal cells and extending to the surface. Cook and Boynton (1952) find a close correlation between stomatal number and penetration. The present writer is inclined to the view that the main entrance to the leaf is through the stomatal pores, for two reasons. First, the penetration into the turgid leaf, with wide-open stomata, is greater than into the wilted leaves whose stomata are partly closed. Secondly, in unreported experiments with $\mathrm{Fe}^{5 \pi}$ we have found that when the solution was applied to the lower surface of the tomato leaf there was a greater absorption than when applied to the upper surface. The lower epidermis of the tomato leaf has about 10 times as many stomata as the upper epidermis. The possibility that the entrance is also effected through other parts of the leaf than the stomata is not excluded because, while penetration through the lower epidermis with the larger number of stomata is greater than through the upper epi- dermis, with fewer stomata, there is no positive correlation between the number of stomata and entrance.

\section{SUMMARY}

The absorption and translocation of cobalt from $\mathrm{Co}^{60} \mathrm{Cl}_{2}$ solution by leaves of bean and cucumber seedlings has been studied. It has been found that absorption is increased by: an increase in light intensity, an increase in temperature and the addition of $\mathrm{S} / \mathrm{V}$ Sovaspray 100 to the isotope solution, but decreased by the wilting of the plants. Absorption but no translocation occurs in plants that have been in the dark from 24 to $72 \mathrm{hr}$., but when sucrose, glucose, fructose or maltose is added to the applied solution there is considerable absorption and translocation, though not nearly so much as in plants in the light. Glycine and mannitol added to the isotope solution did not aid in translocation. Practical applications are that if one is interested in the penetration and distribution of substances sprayed on plants, the spraying should be done in the morning of sunny days unless the soil is dry and the plants likely to wilt, when it should be done in the late afternoon. If spraying has to be done on dark and cloudy days as in winter when the concentration of carbohydrates is likely to be low, sucrose might profitably be added to the spray solution.

\footnotetext{
Departinent of Botany,

UNIVERSITY OF MichIGAN,

AnN Aribor, Michigan
}

\section{LITERATURE CITED}

Bennett, S. H., and D. E. Thomas. 1954. Absorption, translocation and breakdown of Schradan applied to leaves, using P32-labelled material. II. Evaporation and absorption Ann. Applied Biol. 41: 484-500.

Boynton, D. 1954. Nutrition by foliar application. Ann. Rev. Plant Physiol. 5: 31-54.

Cook, J. A., And D. Boynton. 1952. Some factors affecting the absorption of urea by McIntosh apple leaves. Proc. Amer. Soc. Hort. Sci. 59: 82-90.

Emmert, E. M., and J. E. Kurnker. 1950. Spraying tomato foliage with sucrose to increase carbohydrates and protect against injury by urea spraying. Kentucky Agric. Exp. Sta. Bull. 550.

Hircl, H. M. 1953. Increased herbicidal absorption and translocation through the use of an isoparaffinic oil carrier. Abstract, A.I.B.S., 1953 meeting, Madison, Wisconsin.

Mitchell, J. W., And J. W. Brown. 1946. Movement of 2,4-dichlorophenoxyacetic acid stimulus and its relation to the translocation of organic food materials in plants. Bot. Gaz. 107: 393-407.

- AND P. J. Linder. 1949. Methods used in tracing radioactive growth regulating substances in plants. Bureau Plant Industry, Soils, and Agri. Engineering, U. S. D. A. (Mimeographed).
Penfound, W. T., and Virginia Minyard. 1947. Relation of light intensity to effect of 2,4-dichlorophenoxyacetic acid on water hyacinth and kidney bean plants. Bot. Caz. 109: 231-234.

RiCE, E. L. 1948. Absorption and translocation of ammonium 2,4-dichlorophenoxyacetate by bean plants. Bot. Gaz. 109: 301-314.

Roberts. E. A., M. D. Solthwick, and D. H. Palmiter. 1948. A microchemical examination of McIntosh apple leaves showing relationship of cell wall constituents to penetration of spray solutions. Plant Physiol. 23: $557-559$.

Rohrbaugh, L. M., and E. L. Rice. 1949. Effect of application of sugar on the translocation of sodium 2,1-dichlorophenoxyacetate by bean plants in the dark. Bot. Gaz. 111: 85-89.

Weaver, R. J., AND H. R. De Rose. 1946. Absorption and translocation of 2,4-dichlorophenoxyacetic acid. Bot. Gaz. 107: 509-521.

Weintiaub, R. L., and J. W. Brown. 1950. Translocation of exogenous growth regulators in bean seedlings. Plant Physiol. 25: 140-149.

Went, F. W., and Marcella Carter. 1948. Growth response of tomato plants to applied sucrose. Amer. Jour. Bot. 35: 95-106. 